\title{
Screening and analysis of mutation hot-spots in deafness-associated genes among adolescents with hearing loss
}

\author{
HONG JIANG ${ }^{1}$, QIZHEN LIU ${ }^{1,2}$ and LIHONG CHEN ${ }^{1}$ \\ ${ }^{1}$ Department of Otolaryngology - Head and Neck Surgery, Yongchuan Hospital, Chongqing Medical University, \\ Chongqing 402160; ${ }^{2}$ Department of Otolaryngology, People's Hospital of Bayingolin Mongol Autonomous Prefecture, \\ Korla, Xinjiang 841000, P.R. China
}

Received October 2, 2014; Accepted June 18, 2015

DOI: $10.3892 / \mathrm{mmr} .2015 .4475$

\begin{abstract}
The present study aimed to screen the hot-spot deafness gene mutations of adolescents with non-syndromic hearing loss in Yongchuan, Chongqing (CQ-YC ANSHL), aiming to preliminarily understand the region's spectrum and occurrence frequency of deafness gene mutation hot-spots. A total of 60 CQ-YC ANSHL were selected from the Special Education School of Yongchuan, Chongqing and the nine most common mutations of four deafness genes among the Chinese population were detected and associated with the patients' medical history as well as family history of deafness. Deafness gene mutations were detected in 22 cases, among which the detection rates of $G J B 2$, mitochondrial $12 \mathrm{~S}$ ribosomal ribonucleic acid and SLC26A4 mutations were $23.73 \%$ (14/59), 10.17\% (6/59) and 5.08\% (3/59), respectively, while no GJB3 mutation was detected. The carrying rate of deafness gene mutations in CQ-YC ANSHL was high; therefore, based on the deafness gene diagnosis, the combination of medication guidance, pre-natal diagnosis and clinical interventions may be able to effectively reduce the incidence of deafness in this region.
\end{abstract}

\section{Introduction}

According to statistics, one in every 1,000 newborns suffers from pre-lingual deafness and more than half of these cases result from genetic factors (1). Numerous cases of late-onset deafness are additionally due to genetic defects and/or susceptibility to environmental factor (2). The existing medical interventions available for the restoration of hearing are inadequate; thus, the key to the clinical control of deafness

Correspondence to: Dr Hong Jiang, Department of Otolaryngology Head and Neck Surgery, Yongchuan Hospital, Chongqing Medical University, 439 Xuanhua Street, Yongchuan, Chongqing 402160, P.R. China

E-mail: hongjiangdoc@163.com

Key words: non-syndromic hearing loss, hot-spot mutations, genetic diagnosis, gene chip remains predominantly dependent on prevention (3). The first step in the prevention of deafness is to identify the causes of deafness for the existing deaf populations (4). The domestic large-scale molecular epidemiological survey of deafness revealed that there were a number of mutation hot-spots in non-syndromic deaf patients. The carrying rates of GJB2 and SLC26A4 gene mutations have been previously identified to be 21 and $14.5 \%$, respectively, and those of mitochondrial 12S RNA 1555 adenine (A)>guanine (G) and 1494 cytosine $(\mathrm{C})>$ thymine $(\mathrm{T})$ mutations are 3.8 and $0.6 \%$, respectively (5-7). The mutations of these three genes have been identified to be present in humans of various ethnicity (5-7); thus, the discovery of these mutation hot-spots provided a theoretical basis for Chinese researchers to perform the screening, diagnosis and blocking of deafness gene mutations.

Yongchuan district, which is located in the heart of West Chongqing, and has a population of over one million. The health of newborns can be controlled by pre-natal diagnosis and genetic counseling. The early diagnosis of non-syndromic hearing loss is particularly important, and preimplantation genetic diagnosis technology for hereditary deafness, as well as the refusal of ototoxic drugs, hearing aids, and cochlear implants may improve the health of local populations (8). To achieve this, gaining a preliminary understanding of the spectrum and frequency of deafness gene mutation hot-spots in this region is the first step. To the best of our knowledge, no studies have been conducted involving the screening of local non-syndromic hearing loss-associated genes.

In the present study, the Nine Deafness Gene Mutations Detection kit (Boao Biological Co., Ltd., Beijing, China) was applied to perform a microarray-based genetic etiology detection on adolescents with non-syndromic hearing loss in the Yongchuan district (Chongqing, China) (CQ-YC ANSHL), aiming to understand the spectrum and frequency of deafness gene mutation hot-spots in this region, thus providing a theoretical basis for the screening, diagnosis and blocking of deafness gene mutations occurring in this area, and reducing the occurrence and development of deafness in this region.

\section{Materials and methods}

Subjects. In the present study, the CQ-YC ANSHL subjects were selected from the Special Education School (Yongchuan, 
Chongqing, China) between October 2011 and October 2012. Among the 60 subjects, nos. 47 and 55 were siblings and the follow-up statistics solely included the proband; therefore, only no. 47 was included in the statistical analysis. The resulting total sample size was 59, including 30 boys and 29 girls, aged 6-17 years, with a median age of 13 years. The subjects were all Han descendents and residents of Yongchuan district (Chongqing, China). Subsequent to obtaining consent of the guardians, general details regarding the family, family history of deafness, any medical complications of the mother during pregnancy, the patients' medication history, as well as the presence of any head trauma, diseases, deafness development, associated symptoms, and the circumstances of diagnosis and treatment were collected from the patients. In addition, a routine otological examination, overall physical examination and a pure-tone hearing threshold test were performed to exclude syndromic deafness. The included subjects had non-syndromic hearing loss and the deafness degrees were graded according to the results of the pure-tone hearing threshold test, according to the Deaf Classification Standard of the World Health Organization (9). According to whether a family history of deafness was present or not, the 59 patients were divided into two groups. The present study was performed in accordance with the declaration of Helsinki and with approval from the Ethics Committee of Chongqing Medical University (Yongchuan, China). Written informed consent was obtained from the guardians of all participants.

Specimen collection and processing. Subsequent to obtaining informed consent from the guardians, 3-5 ml peripheral venous blood was drawn from each subject and EDTA was added as an anticoagulant. All the specimens were processed using the DP319 Blood Genomic DNA Extraction system (Tiangen Biotech Co., Ltd., Beijing, China) on the same day. The extracted genomic DNA was then quantified with the NanoDrop 2000 Spectrophotometer (Thermo Fisher Scientific, Waltham, MA, USA) to ensure that the DNA concentration was $>100 \mathrm{ng} / \mu 1$ and the purity was confirmed by optical densities at $260 / 280 \mathrm{~nm}$ of 1.7-2.0. The genomic DNA was then stored at $-80^{\circ} \mathrm{C}$.

Microarray analysis and polymerase chain reaction (PCR) amplification. The reagents of the Nine Deafness Gene Mutations Detection microarray kit (Boao Biological Co., Ltd., Beijing, China) were mixed with the PCR-amplified primer mixtures and the amplification reagent mixtures of the two groups in accordance with the manufacturer's instructions. The resulting solution was added into the pre-extracted genomic DNA to prepare the $20 \mu 1$ reaction system for the multiplex PCR. The PCR was conducted with the primers provided in the kit with the following cycling conditions: $37^{\circ} \mathrm{C}$ for $10 \mathrm{~min}, 95^{\circ} \mathrm{C}$ for $15 \mathrm{~min}$ and $96^{\circ} \mathrm{C}$ for $1 \mathrm{~min}$, followed by $94^{\circ} \mathrm{C}$ for $30 \mathrm{sec}$, $55^{\circ} \mathrm{C}$ for $30 \mathrm{sec}$ and $72^{\circ} \mathrm{C}$ for $45 \mathrm{sec}$ for 32 cycles, then $70^{\circ} \mathrm{C}$ for $45 \mathrm{sec}$ and $60^{\circ} \mathrm{C}$ for $10 \mathrm{~min}$. The cooling speed from $94^{\circ} \mathrm{C}$ for to $55^{\circ} \mathrm{C}$ was $0.4^{\circ} \mathrm{C} / \mathrm{sec}$, while the speed of temperature increase from $55^{\circ} \mathrm{C}$ to $72^{\circ} \mathrm{C}$ was $0.2^{\circ} \mathrm{C} / \mathrm{sec}$. The PCR procedure lasted 3 h 20 min, and an CFX96 Quantitative PCR Instrument (BioRad Laboratories, Inc., Hercules, CA, USA) was used.

Hybridization. The PCR products were then placed in a hot bath $\left(95^{\circ} \mathrm{C}\right)$ for $5 \mathrm{~min}$ in order to denature the nucleotides, which were then immediately placed into an ice-water mixture for 3 min. Subsequently, $2.5 \mu \mathrm{l}$ PCR products of each amplification system were added into a tube containing $10 \mu \mathrm{l}$ hybridization-containing buffer, respectively. Following adequate mixing, samples were centrifuged at $157 \mathrm{x} \mathrm{g}$ and added into the chip-array area. The hybrid box was then closed and horizontally placed into the $50^{\circ} \mathrm{C}$-preheated BioMixer ${ }^{\mathrm{TM}} \mathrm{II}$ chips hybridization instrument (Boao Biological Co., Ltd.) for $1 \mathrm{~h}$ with a speed of $80 \mathrm{x} \mathrm{g}$.

Chip washing and drying. The chips were then removed and washed within the SlideWasher ${ }^{\mathrm{TM}}$ 8-chip washing instrument (Boao Biological Co., Ltd.). Washing liquid I $\left(42^{\circ} \mathrm{C}\right)$ was used to wash the chips once for $120 \mathrm{sec}$ with a cleaning force of 5 , then the chips were washed twice with washing liquid II $\left(42^{\circ} \mathrm{C}\right)$ for $60 \mathrm{sec}$ with a cleaning force of 5 . The chips were then put into a drying chamber for centrifugal drying at $241 \mathrm{x} g$ for 2 min.

Scanning and interpretation of results. The dried deafness gene chips were put into the chip-reading window and scanned using the Jingxin LuxScan ${ }^{\mathrm{TM}} 10 \mathrm{~K} / \mathrm{B}$ microarray scanner (Boao Biological Co., Ltd.). The appropriate hereditary genetic testing chip identification system (Jingxin Hereditary Genetic Testing Chip Identification system, version 1.0.2.9; Boao Biological Co., Ltd.) was used to read and automatically interpret the signals.

Statistical analysis. To compare the detection rate of deafness gene mutation hot-spots between groups with or without a clear family history the $\chi^{2}$ test was used. All statistical analyses were conducted using SPSS 17.0 (SPSS, Inc., Chicago, IL, USA).

\section{Results}

Disease history. The deafness degrees of the 59 CQ-YC ANSHL were graded according to the pure-tone hearing threshold test, by which 49 were classified as being of the very severe deafness grade and 10 were classified with the severe deafness grade (the deafness degrees of both ears varied and statistics were determined with regard to the side with better hearing). The onset of deafness ranged between the day of birth and 6 years of age. $77.97 \%$ (46/59) of cases completely lost their language skills and $22.03 \%(13 / 59)$ cases retained limited language skills. A total of 10 cases were identified to have a family history of deafness, with 1-2 deaf individuals within each family.

Genetic testing. The application of the Nine Deafness Gene Mutations Detection microarray kit detected 22 patients with positive deafness gene mutation hot-spots, and the positive rate was $37.29 \%$. Among these, two cases of the GJB2 235 deletion (del) $\mathrm{C}$ homozygous mutation (Fig. 1A); one case of the GJB2 235 del C/176 del 16 complex heterozygous mutation (Fig. 1B); one case of the GJB2 $235 \mathrm{del} \mathrm{C/299}$ del AT complex heterozygous mutation (Fig. 1C); eight cases of the GJB2 235 del C heterozygous mutation (Fig. 1D); one case of the GJB2 299 del AT homozygous mutation (Fig. 1E); one case of the GJB2 35 del G/SLC26A4 IVS 7-2 A>G complex heterozygous mutation (Fig. 1F); two cases of the SLC26A4 IVS 7-2 A>G 
Table I. Deafness-associated factors in adolescents with non-specific hearing loss in Yongchuan district (Chongqing, China).

\begin{tabular}{|c|c|c|c|c|c|}
\hline $\begin{array}{l}\text { Results of deafness mutation } \\
\text { hotspot screening }\end{array}$ & Figure & Cases (n) & Subject nos. & $\begin{array}{l}\text { History of ototoxic } \\
\text { drug application }\end{array}$ & $\begin{array}{l}\text { Family } \\
\text { history }\end{array}$ \\
\hline Blank control & l & / & / & l & l \\
\hline Normal control & l & l & / & l & l \\
\hline Wild-type & 1 & 37 & $\begin{array}{c}44,45,51,30 \\
53 \\
3 \\
54 \\
55 \\
11 \\
32 \\
47 \\
1,2,4,6-9,12,16-20,22 \\
25,28,29,31,34,35 \\
37-41,58\end{array}$ & $\begin{array}{c}\text { Gentamicin } \\
\text { Streptomycin } \\
\text { Uncertain } \\
\text { Uncertain } \\
\text { Uncertain } \\
\text { No } \\
\text { No } \\
\text { No } \\
\text { No }\end{array}$ & $\begin{array}{c}\text { No } \\
\text { No } \\
\text { No } \\
\text { Yes (mother) } \\
\text { Yes (brother) } \\
\text { Yes (brother) } \\
\text { Yes (father } \\
\text { and mother) } \\
\text { Yes (sister) } \\
\text { No }\end{array}$ \\
\hline $\begin{array}{l}\text { GJB2 } 235 \text { del C homozygous } \\
\text { mutation }\end{array}$ & Fig. 1A & 2 & $\begin{array}{l}56 \\
10\end{array}$ & Uncertain & $\begin{array}{c}\text { No } \\
\text { Yes (brother) }\end{array}$ \\
\hline $\begin{array}{l}\text { GJB2 } 235 \text { del C/176 del } 16 \\
\text { complex heterozygous mutation }\end{array}$ & Fig. 1B & 1 & 43 & Gentamicin & No \\
\hline $\begin{array}{l}\text { GJB2 } 235 \text { del C/299 del AT } \\
\text { complex heterozygous mutation }\end{array}$ & Fig. 1C & 1 & 27 & No & No \\
\hline $\begin{array}{l}\text { GJB2 } 235 \text { del C heterozygous } \\
\text { mutation }\end{array}$ & Fig. 1D & 8 & $\begin{array}{c}24,26,50 \\
14,15,33,36,60\end{array}$ & $\begin{array}{c}\text { Gentamicin } \\
\text { No }\end{array}$ & $\begin{array}{l}\text { No } \\
\text { No }\end{array}$ \\
\hline $\begin{array}{l}\text { GJB2 } 299 \text { del AT homozygous } \\
\text { mutation }\end{array}$ & Fig. 1E & 1 & 5 & No & No \\
\hline 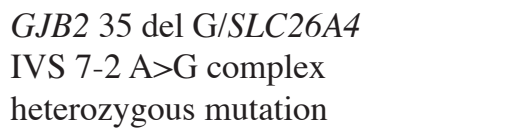 & Fig. 1F & 1 & 57 & Uncertain & No \\
\hline $\begin{array}{l}S L C 26 A 4 \text { IVS } 7-2 \mathrm{~A}>\mathrm{G} \\
\text { heterozygous mutation }\end{array}$ & Fig. 1G & 2 & $\begin{array}{l}13 \\
46\end{array}$ & $\begin{array}{l}\text { No } \\
\text { No }\end{array}$ & $\begin{array}{c}\text { No } \\
\text { Yes (mother) }\end{array}$ \\
\hline Mitochondrial 12S rRNA $1555 \mathrm{~A}>\mathrm{G}$ & Fig. 1H & 6 & 49,52 & Gentamicin & No \\
\hline & & & 42 & Gentamicin & $\begin{array}{l}\text { Yes ( mother } \\
\text { and cousin) }\end{array}$ \\
\hline & & & $\begin{array}{l}48 \\
23 \\
21\end{array}$ & $\begin{array}{c}\text { Gentamicin } \\
\text { No } \\
\text { No }\end{array}$ & $\begin{array}{l}\text { Yes (brother) } \\
\text { Yes (mother) } \\
\text { No }\end{array}$ \\
\hline Total & & 59 & & $\begin{array}{c}13 \text { (certain), } \\
5 \text { (uncertain), } \\
41 \text { (no medication) }\end{array}$ & $\begin{array}{c}10 \text { (family } \\
\text { history); } \\
49 \text { (no family } \\
\text { history) }\end{array}$ \\
\hline
\end{tabular}

Among the 60 cases, no. 47 and no. 55 were siblings, so the follow-up statistics included only the proband. Therefore only no. 47 was included in the analysis and the total sample size was 59 cases. del, deletion.

heterozygous mutation (Fig. $1 \mathrm{G}$ ) and six cases of mitochondrial 12S rRNA $1555 \mathrm{~A}>\mathrm{G}$ homogeneous mutation (Fig. 1H) were identified. The results of the deafness mutation hot-spots screening, history of ototoxic drug application and family 


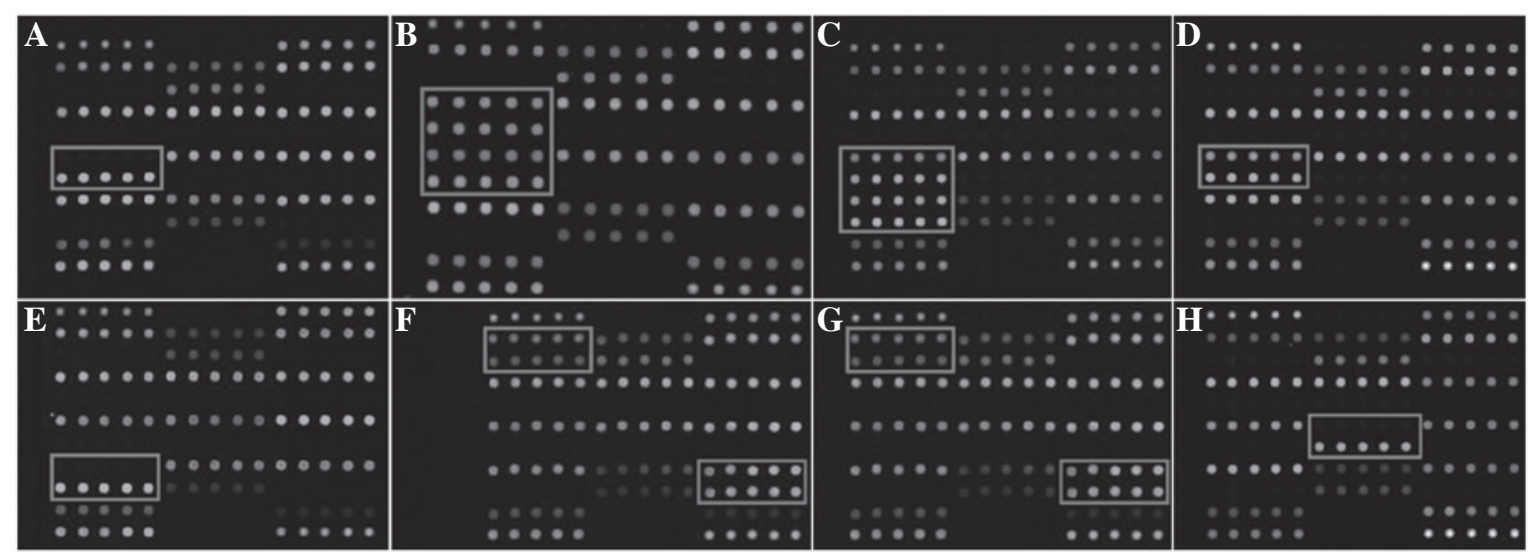

Figure 1. Microarray analysis for deafness gene mutations. (A) GJB2 235 del C homozygous mutation; (B) GJB2 235 del C/176 del 16 complex heterozygous mutation; (C) GJB2 235 del C/299 del AT complex heterozygous mutation; (D) GJB2 235 del C heterozygous mutation; (E) GJB2 299 del AT homozygous mutation; (F) GJB2 35 del G/SLC26A4 IVS 7-2A>G complex heterozygous mutation; (G) SLC26A4 IVS 7-2A>T heterozygous mutation; (H) mitochondrial $12 \mathrm{~S}$ rRNA $1555 \mathrm{~A}>\mathrm{G}$ homogeneous mutation. del, deletion.

history of deafness are presented in Table I and the deafness chip scanning results of certain selected subjects are presented in Fig. 1. The comparison between the groups with or without a clear family history gave a $\mathrm{P}$-value $>0.05\left(\chi^{2}=0.306, \mathrm{P}=0.580\right)$; thus, no statistical significance was observed.

\section{Discussion}

Genetic factors have been reported to influence the development of deafness; thus, through identifying genetic factors of deaf patients and high-risk groups and giving appropriate guidance and interventional measures, the new-onset and aggravation of deafness may be prevented to a certain extent (10). To date, numerous deafness genes have been identified and the mutation spectrum is known to be widespread. The identification of deafness gene mutation hot-spots in domestic non-syndromic deaf patients has made it feasible to investigate the associated causes.

GJB2 was the first disease-causing gene identified for Chinese non-syndromic hearing loss (11) and in the present study, the detection rate of the GJB2 mutation in CQ-YC ANSHL was $23.73 \%$ (14/59), accounting for $63.64 \%$ of all positive mutations (14/22). A total of five cases of the GJB2 homozygous or complex heterozygous mutation were identified to be the cause of deafness, and the remaining nine cases of the GJB2 heterozygous mutation (including one case of GJB2 35 del G/SLC26A4 IVS 7-2A>G complex heterozygous mutation) had no family history of deafness. According to Mendelian inheritance (12), these cases were identified as the autosomal recessive heredity mode; however, the single $G J B 2$ allelic mutation could not be determined as the cause of deafness, as the co-existence of additional possible factors associated with deafness should be considered. GJB2 235 del C was observed to be the most common deafness-associated mutation in Yongchuan district in the cohort of the present study, accounting for $73.68 \%$ (14/19) of all gene mutation loci detected, followed by 299 del AT, accounting for $15.79 \%$ (3/19). The present study detected one case of a35 del $\mathrm{G}$ mutation, and this patient's family had lived in the local area for numerous years, with no descent from any ethnic minority and no family history of deafness; thus, it was suggested that a rare recessive genetic cause of deafness was present in this patient within the Yongchuan district.

A previous study observed that in one patient, the mitochondrial $12 \mathrm{~S}$ rRNA gene mutation was associated with maternal inheritance, and the application of aminoglycosides resulted in irreversible hearing loss (13). In the present study, the detection rate of mitochondrial $12 \mathrm{~S}$ rRNA $1555 \mathrm{~A}>\mathrm{G}$ mutation was $10.17 \%$ (6/59), while the $1494 \mathrm{C}>\mathrm{T}$ mutation was not detected; among the six positive patients, three patients had a family history of deafness and four cases had a history of application of aminoglycoside drugs (gentamicin). This result was higher than that reported by Dai et al (5) and Yuan et al (6), suggesting that the frequency of the mutation of the mitochondrial 12S rRNA gene was increased in the Yongchuan district. Screening towards deafness-associated mutations in Yongchuan may aid in effectively identifying a large number of individuals with this gene mutation, sensitivity to aminoglycoside drugs and normal hearing abilities, who inherited the mutation from maternal relatives. Thus, through education and application of medication, the deafness of high-risk groups may be avoided, and in addition, scientific genetic counseling, pre-natal diagnosis and intervention may be performed over several generations, thus blocking the passing on of this gene mutation in the family.

The SLC26A4 gene mutation has been previously reported to result in non-syndromic hearing loss and syndromic deafness $(14,15)$. The present study detected two cases of the SLC26A4 IVS 7-2A>G single heterozygous mutation and one case of the GJB2 35 del G/SLC26A4 IVS 7-2 A>G complex heterozygous mutation in CQ-YC ANSHL. The detection rate of the SLC26A4 IVS 7-2A $>\mathrm{G}$ mutation was $5.08 \%(3 / 59)$, accounting for $13.64 \%(3 / 22)$ of all positive mutations, while the $2168 \mathrm{~A}>\mathrm{G}$ mutation was not detected. A total of three cases had no history of significant head trauma and high fever, only one case of the SLC26A4 IVS 7-2A>G single heterozygous mutation had a family history of deafness. To date, $>150$ cases of the SLC26A4 gene mutation have been reported (16); however, the test results were limited by the numbers and types of microarray deafness gene mutation points and thus, not all known SLC26A4 gene mutations could 
be detected. Further gene sequencing of the patients with the SLC26A4 IVS 7-2A>G single heterozygous mutation may be beneficial in elucidating the cause of their deafness. In the present study, the detection rate of the SLC26A4 mutation was lower than that reported in previous studies $(17,18)$, and the possible causes are as follows: i) The SLC26A4 mutation is involved in the development of large vestibular aqueduct syndrome (19), which commonly manifests as acquired deafness. This deafness is progressive, and hearing aids and speech training are capable of significantly improving hearing and speech ability; thus, these patient may not have to enrolled in a special education school and were thus not recruited for the present study (20). ii) Differences may exist in the deafness gene mutation spectrum in Yongchuan, as reported by Dai et al (5) and Yuan et al (6).

The present study analyzed the impact of the genetic background on the detection rate of deafness gene mutation hot-spots. The results demonstrated that there was no statistical significance between the groups with or without a family history of deafness $\left(\mathrm{P}>0.05 ; \chi^{2}=0.306\right)$. In addition, the genetic background had no effect towards the detection rate of deafness gene mutation hot-spots. This was considered to be due to the fact that as deafness gene mutations detected by the microarray were predominantly recessive or from maternal inheritance, the participants were often carriers, but were not necessarily deaf.

Previous studies have demonstrated that the detection rate of single deafness gene mutation hot-spot screening is not high, and for $>50 \%$ of deaf patients, the genetic causes of deafness are not clear; thus, the detection method and integrated assessment tools require improvement $(21,22)$. In the present study, the mutation-positive rate was $37.29 \%$ (22/59), while $62.71 \%(37 / 59)$ of patients carried the respective wild-type genes. Subjects no. 47 and 55 were siblings, and the deafness gene mutation hot-spot screening showed that they were the wild-type; furthermore, there was no other deaf patient in their family, and there fore, their mutation is likely to be of a recessive hereditary type. However, mutations of genes other than the nine common deafness-associated genes examined in the present study may have been the underlying cause, and therefore, further investigation of the causes of the deafness of patients no. 47 and 55 is required. The present study hypothesized that with the advances in gene chip technology and in-depth research of the genetic causes of deafness, additional deafness-associated mutations may be covered, and individual screening against the mutation spectrum may be undertaken in order to assess the occurrence frequency in various regions and in patients of different ethnicities. Therefore, using these techniques may aid in the determination of the genetic causes of deafness.

The Yongchuan area is located in West Chongqing and has a large population; genetic counseling with regard to mutation-associated deafness is important to block the inheritance of genetic deafness and improve the health of the local population. In the present study, questionnaire-based statistics regarding the CQ-YC ANSHL showed that in $11.86 \%(7 / 59)$ of cases, a history of deafness was present in the family, the mother did not receive any genetic counseling or risk assessment prior to the pregnancy. There were numerous neglected children in the region whose abnormalities were being ignored during their growth and development. Thus, deafness was not identified early and due to the lack of formal training in hearing aids and speech therapy, the patients' language-communication skills and quality of life were severely affected. Medical staff and parents are required to take early symptoms of deafness in children and young people seriously, as once they are diagnosed as deaf, a timely and appropriate treatment should be performed. At the same time, the genetic cause of their deafness should be determined to prevent the progression of deafness in future generations. In addition, the present study showed that the rate of non-syndromic hearing loss-associated gene mutations among adolescents in the Yongchuan district was elevated compared with that in other regions, suggesting that the government and medical institutions should intensify genetic counseling and pre-natal diagnosis of genetic diseases using existing tools, including genetic diagnosis, in order to screen deaf patients and high-risk groups for deafness gene mutations. The combination of guidance on medication, pre-natal diagnosis and clinical intervention may reduce deafness in the population.

\section{Acknowledgements}

The authors would like to thank Ms Dan Zhang, Ms Jianmin Wang and Ms Juan Liao (Molecular Biology Laboratory and Central Laboratory of Yongchuan Hospital, Chongqing Medical University, Chongqing, China) and all staff, students and parents of Chongqing Yongchuan Special Education School (Chongqing, China) for their support and help.

The present study was supported by the Science and Technology Research Project of Chongqing Municipal Education Commission (grant no. KJ110326) and the Hospital Project of Yongchuan Hospital, Chongqing Medical University (grant no. YJYB201025).

\section{References}

1. Morton NE: Genetic epidemiology of hearing impairment. Ann N Y Acad Sci 630: 16-31, 1991.

2. Chen G, Wang X and Fu S: Prevalence of A1555G mitochondrial mutation in Chinese new borns and the correlation with neonatal hearing screening. Int J Pediatr Otorhinolaryngol 75: 532-534, 2011

3. Géléoc GS and Holt JR: Sound strategies for hearing restoration. Science 344: 1241062, 2014.

4. Taneja MK: Preimplantation genetic diagnosis: Its role in prevention of deafness. Indian J Otolaryngol Head Neck Surg 66: 1-3, 2014.

5. Dai P, Yu F, Han B, Yuan Y, Li Q, Wang G, Liu X, He J, Huang D, Kang D, et al: The prevalence of the 235delC GJB2 mutation in a Chinese deaf population. Genet Med 9: 283-289, 2007.

6. Yuan Y, You Y, Huang D, Cui J, Wang Y, Wang Q, Yu F, Kang D, Yuan H, Han D, et al: Comprehensive molecular etiology analysis of nonsyndromic hearing impairment from typical areas in China. J Transl Med 7: 79, 2009.

7. Du W, Wang Q, Zhu Y, Wang Y and Guo Y: Associations between GJB2, mitochondrial 12S rRNA, SLC26A4 mutations and hearing loss among three ethnicities. Biomed Res Int 2014: 746838, 2014.

8. Yin A, Liu C, Zhang Y, Wu J, Mai M, Ding H, Yang J and Zhang X: Genetic counseling and prenatal diagnosis for hereditary hearing loss in high-risk families. Int J Pediatr Otorhinolaryngol 78: 1356-1359, 2014.

9. Huang XH, Wang JB and Kong WJ: Practice of Otorhinolaryngology-Head and Neck Surgery. 2nd Edition. People's Medical Publishing House, Beijing, p1006, 2007. (In Chinese). 
10. De Keulenaer S, Hellemans J, Lefever S, Renard JP, De Schrijver J, Van de Voorde H, Tabatabaiefar MA, Van Nieuwerburgh F, Flamez D, Pattyn F, et al: Molecular diagnostics for congenital hearing loss including 15 deafness genes using a next generation sequencing platform. BMC Med Genomics 5: 17, 2012.

11. Yu F, Han DY, Dai P, Kang DY, Zhang X, Liu X, Zhu QW, Yuan YY, Sun Q, Xue DD, et al: Mutation of GJB2 gene in nonsyndromic hearing impairment patients: Analysis of 1190 cases. (Article in Chinese). Zhonghua Yi Xue Za Zhi 87: 2814-2819, 2007 (In Chinese).

12. Kenneson A, Van Naarden Braun K and Boyle C: GJB2 (connexin 26) variants and nonsyndromic sensorineural hearing loss: A HuGE review. Genet Med 4: 258-274, 2002.

13. Chen T, Liu Q, Jiang L, Liu C and Ou Q: Mitochondrial COX2 G7598A mutation may have a modifying role in the phenotypic manifestation of aminoglycoside antibiotic-induced deafness associated with $12 \mathrm{~S}$ rRNA A1555G mutation in a Han Chinese pedigree. Genet Test Mol Biomarkers 17: 122-130, 2013.

14. Prak HJ, Shaukat S, Liu XZ, Hahn SH, Naz S, Ghosh M, Kim HN Moon SK, Abe S, Tukamoto K, et al: Origins and frequencies of SLC26A4 (PDS) mutations in east and south Asians: Global implications for the epidemiology of deafness. J Med Genet 40: 242-248, 2003

15. Hutchin T, Coy N, Conlon H, Telford E, Bromelow K, Blaydon D Taylor G, Coghill E, Brown S, Trembath R, et al: Assessment of the genetic causes of recessive childhood non-syndromic hearing loss in the UK-implications for genetic testing. Clin Genet 68: 506-512, 2005.
16. Bizanova A and Kopp P: Genetics and phenomics of pendred syndrome. Mol Cell Endocrinol 322: 83-90, 2010.

17. Dai P, Li Q, Huang D, Yuan Y, Kang D, Miller DT, Shao H, Zhu Q, He J, Yu F, et al: SLC26A4c.919-2A>G varies among Chinese ethnic groups as a cause of hearing loss. Genet Med 10: 586-592, 2008

18. Jiang H, Chen J, Shan XJ, Li Y, He JG and Yang BB: Prevalence and range of GJB2 and SLC26A4 mutations in patients with autosomal recessive non-syndromic hearing loss. Mol Med Rep 10: 379-386, 2014.

19. Yuan Y, Guo W, Tang J, Zhang G, Wang G, Han M, Zhang X, Yang S, He DZ and Dai P: Molecular epidemiology and functional assessment of novel allelic variants of SLC26A4 in non-syndromic hearing loss patients with enlarged vestibular aqueduct in China. PLoS One 7: e49984, 2012

20. Zhu YM, Guo YF, Liu XW, Wang Y, Xu B, Ji Y, Li J, Li Z and Wang Q: The hereditary etiology analysis of deaf students from Shaanxi province. J Audiol Speech Pathol 18: 225-228, 2010.

21. Alford RL, Arnos KS, Fox M, Lin JW, Palmer CG, Pandya A, Rehm HL, Robin NH, Scott DA, Yoshinaga-Itano C, et al: American college of medical genetics and genomics guideline for the clinical evaluation and etiologic diagnosis of hearing loss. Genet Med 16: 347-355, 2014.

22. Levenson D: New testing guidelines for hearing loss support next-generation sequencing: Testing method may help determine genetic causes of hearing loss among patients whose phenotypes are not easily distinguished clinically. Am J Med Genet A 164: vii-viii, 2014. 